\title{
LA MEMORIA INDIVIDUAL Y LAS HISTORIAS DE VIDA COMO FUENTES PARA EL ANÁLISIS DE LAS RECIENTES MIGRACIONES LATINOAMERICANAS A ESPAÑA. UN PLANTEAMIENTO METODOLÓGICO DESDE LA HISTORIA ORAL
}

\author{
Fernando L. García de Sola Márquez \\ Universidad de Cádiz
}

\section{$\underline{R E S U M E N}$}

El presente artículo es una reflexión sobre la validez de la utilización de la memoria individual y de las Historias de Vida como fuentes primordiales para la investigación de las recientes migraciones exteriores latinoamericanas. Así, usando como ejemplo el estudio de las migraciones latinoamericanas a España en el cambio de siglo, pretendemos defender la utilización de la Historia Oral como la manera más adecuada de acercarse de forma cualitativa a este fenómeno, destacando en nuestra perspectiva la especial atención que gracias a esta metodología se puede prestar a los aspectos más humanos del hecho migratorio.

Palabras clave: América Latina, España, migraciones, Historia Oral.

\section{ABSTRACT}

The following article is a reflection about the validity in using individual memories and life stories as sources of information in studies regarding the recent migration of Latin Americans to other countries. Using the example of Latin American migrations to Spain at the end of $20^{\text {th }}$ century, we attempt to defend the use of Oral History as the best method, and in our opinion, the method that gives special attention to the most human aspects of this migration.

Keywords: Latin America, Spain, 20 $0^{\text {th }}$ century, Migration, Oral History. 
Este artículo nace del deseo de establecer una metodología de investigación adecuada para analizar, desde una perspectiva histórica, los aspectos más humanos de los movimientos migratorios que, de manera significativa, han marcado el reciente cambio de siglo, un fenómeno global que en Latinoamérica se ha vivido de forma particularmente intensa a partir de las últimas décadas del pasado siglo XX.

Si en los años setenta los exiliados por las dictaduras militares fueron los principales protagonistas ante el mundo de la diáspora latinoamericana, en las décadas siguientes (denominadas por algunos autores como década perdida, la de los años ochenta, y de la exclusión, la de los noventa), la crisis generalizada que afecta en mayor o menor medida a prácticamente todos los países de la región, provocará que, como consccuencia de la aplicación de un duro sistema de ajustes económicos de corte neoliberal, la emigración exterior se convierta en la principal válvula de escape de una población latinoamericana que buscará en los países receptores las oportunidades de mejora que se le niega en sus lugares de origen. Así, ante el progresivo aumento de la pobreza, del desempleo y del subempleo, acompañado de la crisis de expectativas y el efecto dominó que se crea en algunas regiones con la constatación de las mejoras económicas de aquellas familias que tienen miembros en el extranjero, las motivaciones sociales y económicas han ido desplazando en muchos casos a los ya referidos motivos políticos, para configurar una diáspora cada vez más numerosa que, desgraciadamente, en la mayoría de las ocasiones ha sido tratada por los investigadores de una forma puramente cuantitativa, sin detenerse en las vivencias personales de sus protagonistas ni en sus aspectos más humanos, tanto desde el punto de vista social como personal.

Frente al silenciamiento de la memoria individual y colectiva que muchas veces se esconde en la exposición científica de las cifras y de los balances migratorios, la metodología de investigación que proponemos en este artículo se basa esencialmente en escuchar y dar la palabra a los protagonistas del fenómeno migratorio, es decir, en escuchar a los que han vivido y, por ello, saben ${ }^{1}$, pero haciéndolo no sólo desde la frialdad aparentemente científica de los estudios supuestamente objetivos, sino desde unas vivencias compartidas y desde la humana certeza de la imposibilidad de conseguir una objetividad absoluta en la percepción de un fenómeno de tanta relevancia en la actualidad.

Como premisa, hemos de advertir que la forma de hacer Historia que describimos en este artículo surge de la necesidad de hacer una Historia distinta a la oficial, una Historia de vivos que sirva para transformar el mundo desigual e injusto que nos ha tocado vivir ${ }^{2}$, pues al devolver la palabra a los marginados por la oficialidad, a los $\sin v o z$, les estamos dando también un instrumento para analizar su propia historia, para indagar en su memoria e interpretar su presente ${ }^{3}$.

I BERTAUX-WIAME. Isabelle, "La perspectiva de la historia de vida en el estudio de las migraciones interiores", en: MARINAS, J.M. y SANTAMARINA, C. (cds.). La Hisforia Oral Metodos v experienciax, Madrid, Debate, 1993, p. 281.

2 PÉREZ MURILLO, $\mathrm{M}^{\mathrm{n}}$. Dolores (coord.), Oralidad e historias de vida de la emigración andaluza hacia América Latina (Brasil y Argentina) en ei sigio XX, Cádiz, Servicio de Publicaciones de la Universidad de Cádiz, 2000, p. 21.

3 "La auténtica justificación de la Historia no es inmortalizar a unos cuantos viejos: forma partc del modo en que los vivos se explican su propio lugar y su propio cometido en el mundo. (...) Al colaborar a demostrar cómo sus propias historias responden al carácter cambiante del lugar en que viven. a sus problemas en cuatno trabajadores o padres, la Historia puede ayudar a la gente a ver dónde se encuentra y adónde tendría que ir. (...) La historia oral le deruelve a la gente la Historia en sus propias palabras. $Y$ al tiempo que les hace entrega de un pasado, les suministra tambien un punto de apoyo de cara a un futuro construido por ellos mismos", THOMPSON, Paul, La voz del pasado. Historia Orch, Valencia, Edicions Alfons el Magnànim, 1988, p. 297. 
Sin duda, este planteamiento no es del todo novedoso, pues algunos de sus antecedentes más inmediatos han cumplido ya el cuarto de siglo, pero ciertamente, a pesar de los años transcurridos desde sus primeras formulaciones ${ }^{4}$, la Historia Oral, y concretamente la que parte directamente de las historias de vida, ha venido siendo hasta ahora la gran ausente en muchos circulos oficiales y, aún hoy, resulta dificil encontrar trabajos científicos sobre movimientos migratorios en los que la fuente oral prime sobre las series estadísticas o los registros puramente demográficos ${ }^{5}$.

Como creo que nos ocurre a la mayoría de los historiadores, la elección de este campo de investigación y de esta forma concreta de hacer Historia, nos vino dada a partir de una experiencia personal. Así, mi pasión por esta manera de enfocar los estudios migratorios surge durante mi estancia en Cuenca, en el Austro Ecuatoriano, en compañia de la Dra. Pérez Murillo, durante los meses de octubre y noviembre de 1997, cuando percibimos que muchas personas que habian vivido de cerca, tanto directa como indirectamente, las consecuencias de la emigración internacional se nos presentaban deseosas de compartir sus experiencias con nosotros, de contarnos su personal e irrepetible vivencia del proceso migratorio y de las consecuencias que este fenómeno había provocado en su particular percepción de la realidad. El contacto directo con estas personas y la recogida de sus testimonios fue, por tanto, el comienzo de la línea de trabajo que a lo largo de estos últimos años hemos ido madurando y que ha dado lugar al planteamiento metodológico expuesto en este artículo y, si como defiende Mercedes Vilanova, historiar es, sobre todo, dialogar con los otros ${ }^{6}$, debemos entonces confesar que nuestra auténtica carrera como historiador comenzaría con esos diálogos de 1997.

Por supuesto, la mera recogida del testimonio no nos convierte de la noche a la mañana en historiadores y detrás de la elaboración de una historia de vida y de un

4 La primera edición inglesa del libro de Paul Thompson se remonta a 1978 (The voice of the past, Oxford University Press, 1978), mientras que otra obra clave en la consolidación de la perspectiva de la Historia Oral, el libro de IRASER, Ronald, Recuérdalo á y recierdalo a otros. Historia Oral de la Guerra Civil expañola, fue publicado en español por la Editorial Critica en 1979.

5 Afortunadamente, en los últimos años las tendencias van cambiando y empiezan ya a aparecer estudios sobre migraciones basados en la oralidad en diversas publicaciones y congresos. Así, el ya citado trabajo de Isabclle BERTAUXWIAME (véase nota 11, o los articulos publicados en difcrentes numeros de las revistas Historia y Fueme Oral o Historia, Antropologiay. Fuentes Orales (publicadas por la Universitat de Barcelona). También quisiéramos cilar las comunicaciones presentadas en el "Il Congreso sobre la migración en España" (entre las que destacamos, por la alinidad entre sus contenidos y alguna de las propuestas que hoy presentcmos, la claborada por OSO CASAS, Laura. Estrategias migratorias de las mujeres ectatorianas y colombianas en siluación irregular: Servicio domésico y prostinción én Galicia y Pamplona), o los trabajos realizados en la Universidad de (uenca (Ecuador) sobre migración femenina. Destacamos tambićn los trabajos que en el ámbito de nucstro Grupo de Irvestigación Intrahistoria. Oralidad y Culnura en América Latina y Andalucia, viene desarrollando y dirigiendo la doctora M ${ }^{2}$ Dolores PÉRL $\angle$ MURILLO, entre los cuales encontramos las investigaciones de Eva M $\mathrm{M}^{\mathrm{D}}$ DIZ BUZON sobre inmigrantes ecuatorianos de origen saraguro en Andalucia Oriental (DIAZ. BLZON. Fva $\mathrm{M}^{3}$, Los indigenas saraguros (Republica de Ecuador) y su emigración a Vera (Almeria) a tranés de la Historia Oral. Tesis Doctoral dirigida por PEREZ MURILLO, $\mathbf{M}^{\mathrm{a}}$ Dolores. defendida en la Universidad de Cádiz en Septiembre de 2003). Por otro lado, destacariamos también los trabajos que, desde el IJepartamento de Antropologia del CSIC, viene realizando Margarita del OLMO, cenIrados sobre todo en el cxilio argentino en España (OLMO, Margarita del, La Liopia en el Exilio, Madrid, 2002). Asimismo, también consideramos relevantes las aportaciones de la doctora Beatriz VITAR sobre migraciones siriolibanesas a América latina, si bien eslas van más releridas a la integración de las diferentes generaciones de inmigrantes en los paises de acogida que al proceso migratorio en sí (véasc. a modo de cjemplo, ViTAR. Beatriz, "Inmigrantes sirios y libaneses en Tucumán (Argentina). El reclamo de la etnicidad". en Trocadero, n" 10-11 (19981999), p. 287-308) o las aportaciones sobre la inmigración peruana a España de Asunción MFRINO HERNANDO. aunque en ćstc último caso priman las fuentes documentales sobre los testimonios oralcs.. 
artículo o un libro basado en ésta hay todo un proceso de reflexión, de investigación y de interpretación, que es lo que pretendemos describir a continuación, pues para hacer Historia Oral no basta sólo con escuchar a nuestros informantes y transcribir sus testimonios, sino que hay que hacerlo con una actitud particular y con unos conocimientos previos bien asentados, pues sólo así podremos interpretar a través de las palabras y de los silencios de nuestros informantes los retazos de Historia que surgen de su memoria.

No voy a entrar aquí en la reiterada discusión sobre la subjetividad de la memoria individual y del testimonio oral, ni sobre sus aparentes desventajas sobre otras fuentes de la Historia, ni me voy a referir tampoco a la polémica generada en torno a si la Historia Oral es sólo una forma de acceder a unas fuentes, una técnica, una metodología o una ciencia meramente auxiliar de otra Historia que se presupone más seria, pues creo que el tema ya ha sido bien expuesto y debatido en otros foros ${ }^{7}$, pero sí me voy a referir a la Historia Oral, y en concreto a la que utiliza como base las historias de vida, como una forma única e insustituible de acceder a la compresión de los fenómenos migratorios recientes.

Efectivamente, en un fenómeno en el que la invisibilidad oficial de sus protagonistas es un elemento no sólo relevante sino esencial para comprender la magnitud y la naturaleza de sus repercusiones, la fuente oral, el testimonio directo, se convierte en un recurso indispensable para el historiador. Si un alto porcentaje de la población latinoamericana que reside en España lo hace sin papeles, parece evidente que cualquier estudio que se circunscriba al ámbito estricto de las fuentes documentales oficiales nace mutilado desde el principio. Sin fuentes oficiales a las que recurrir sin cuestionar su fiabilidad, la entrevista directa se presenta como la fuente principal a la que interrogar. Pero, ¿significa esto una renuncia total a la utilización de otras fuentes? Por descontado, la respuesta a esta pregunta ha de ser siempre "No". Las estadísticas oficiales y los estudios de corte puramente demográfico, apoyarán las ideas previas que sobre la magnitud del fenómeno migratorio podamos ir elaborando, y por tanto no conviene olvidarse totalmente de ellas, si bien, teniendo siempre presente que su valor para nosotros ha de ser puramente orientativo. Por otro lado, nuestra experiencia nos ha venido demostrando que la utilización de las fuentes periodisticas y de la literatura de creación como referentes esenciales de nuestros estudios han sido siempre muy provechosas como contraste y complemento de la fuente oral, pues no sólo completan la información que ésta nos aporta, sino que se nos muestran tremendamente útiles a la hora de analizar las imágenes que los protagonistas de las migraciones proyectan en la sociedad. En este sentido, también hemos de señalar que el cine de creación de temática migratoria ha sido también un referente notable en nuestras investigaciones, aportando valiosas informaciones acerca de la imagen creada en torno al fenómeno migratorio ${ }^{8}$.

7 Sobre estos particulares me parecen bien significativas las frecuentes manifestaciones de Paul THOMPSON, o el artículo de PRINS, Guyn, "Historia Oral", en Historia y Fuente Oral, $n^{\circ} 9$ (1993), pp. 21-43, y los comentarios a dicho trabajo de Cristina BORDERIAS, Ronald FRASER. José A. G. ALCANTUD, Ignasi TERRADAS y Mercedes VILANOVA, conlenidos en el mismo número, pp. 45-51, destacando la afirmación de PRINS: "La fuerza de la historia oral es la de eualquier historia que tenga una seriedad metodológica. Esta fuerca procede de la diversidad de las fuentes consultadas y de la inteligencia con que se han utilizado".

8 Valga como ejemplo el capitulo desarrollado bajo el titulo de "Somos andando" en el libro de PÉREZ MURILLO, M. D. y FERNÁNDEZ FERNÁNDEZ. D. (coordinadores), La Memoria Filmada. América Latina a Iranés de su cine, Madrid, IFPALA, 2002, en el cual se analizan a través del cstudio de diversas peliculas las distintas imágenes que sobre los movimientos migraiorios se proyectan socialmente. 
Como vemos pues, nuestra Historia Oral de las recientes migraciones latinoamericanas a España se sustenta no sólo sobre el testimonio grabado, sino sobre unos conocimientos y unos elementos de análisis que enriquecen las aportaciones de nuestros informantes. Como ya hemos señalado anteriormente, se trata de escuchar, sí, pero no sólo de escuchar. También hay que comparar, interpretar, completar y, ¿por qué no?, incluso, imaginar, aunque dejando claro que este imaginar no consiste en inventar la Historia, sino en saber trazar los puentes entre los testimonios y las otras fuentes, entre éstas y las mentalidades que las crearon, entre lo individual y lo social, tarea para la cual, la imaginación, entendida como un saber entender dónde otros no ven, me parece una cualidad fundamental.

Ahora bien, no sólo escuchar, pero sí al fin y al cabo partir de la escucha, del diálogo, por lo que inmediatamente se nos plantean dos interrogantes: ¿Cómo hemos de escuchar? Y, ¿a quiénes hemos de escuchar?.

Respondamos primero a esto último: ¿A quiénes hemos de escuchar? O dicho de otra forma, ¿cómo hemos de seleccionar a nuestros informantes? Aquí, sobre cualquier formulación teórica se impone la práctica, y es el propio trabajo de campo el que nos va guiando hacia nuestros informantes.

Anteriormente, nos referiamos a las circunstancias vividas durante nuestra estancia en Ecuador, cuando fueron muchas las personas que se dirigieron a nosotros de manera más o menos espontánea a contarnos sus experiencias migratorias. Lo cierto es que, en aquella ocasión, nos hallábamos impartiendo un taller sobre Intrahistoria y Oralidad de la migración andaluza a América y, a raiz de verse reflejados en las historias que nosotros relatábamos, nuestros interlocutores nos hicieron partícipes de sus experiencias, pues prácticamente todos conocían a alguien, o tenían un amigo o un familiar que había emigrado a los Estados Unidos de Norteamérica. Surgieron así unas redes de información que nos permitieron seguir el rastro de diversas historias $\mathrm{y}$, a través del contacto directo con emigrantes retornados o con testigos indirectos (amigos y familiares de personas emigradas), pudimos recopilar material suficiente para hacer nuestra primera incursión en la Historia Oral de la emigración latinoamericana9. Pero a la hora de ampliar estas investigaciones y de plantear el estudio de la migración latinoamericana a España, esta espontaneidad parecía menos probable y por tanto habría que buscar otra manera de contactar con potenciales informantes.

El impulso inicial fue contactar con asociaciones de inmigrantes y, aunque éste ha sido uno de los recursos utilizados, ciertamente, en muchos casos se ha impuesto, al final, esa espontaneidad a la que antes hacíamos referencia, pues en cuanto entras en contacto con un grupo de inmigrantes, bien sea a través de las asociaciones, bien a través de nuestro propio trabajo en la Universidad de Cádiz, bien por otros medios, comienzan a aparecer formas de contactar con otros inmigrantes, o con personas que trabajan con ellos, o con vecinos u otros testigos indirectos. Sin duda, se podrá achacar a este método de selección que no parece una forma muy científica de seleccio-

9. El resultado de csta investigación fuc prescntado como Tesina de Licenciatura en la Cniversidad de Cádiz en noviembre de 2001, bajo el título de La emigración indoctmentada latinaamericana a los Estados Linidos a travé: de las testimonios orales y de la prensa. El caso del Austro Echatoriano. 
nar una muestra significativa según los parámetros tradicionales de las Ciencias Sociales, pero en nuestra defensa hemos de argüir que aunque aparentemente no sea muy objetiva, sí es la manera más efectiva de conocer y entablar conversación con personas que muchas veces se mueven a espaldas de lo que se considera el orden legal establecido. Además, tras convivir con ellos y recoger sus historias de vida, hemos podido comprobar que cada historia es personal e irrepetible, y que para buscar la parte humana del fenómeno migratorio, esa que no reflejan las cifras, ni las estadísticas, ni las encuestas cerradas, lo importante no es acumular testimonios extraídos a partir de muestras de población calculadas mediante complicadas operaciones informáticas, sino saber escuchar a quiénes estén dispuestos a compartir sus palabras, sus gestos y sus silencios. Por otro lado, el recurso exclusivo al contacto a través de asociaciones o de grupos más o menos organizados de inmigrantes, supone el riesgo de que las opiniones vertidas por sus miembros se diluyan en las posturas más o menos oficiales que cstas instituciones proclaman, perdiéndose con demasiada frecuencia la espontaneidad y sinceridad que buscamos en nuestros informantes, y de ahi, también, que la diversificación de los ámbitos de contacto nos parezca la postura más adecuada.

$Y$ tras estas apreciaciones, demos respuesta a continuación al otro interrogante que planteábamos anteriormente: ¿Cómo debemos escuchar? Y, consecuentemente, ¿cómo debemos preguntar? Es decir, ¿ cómo debemos plantear y estructurar la entrevista? ${ }^{10}$

En primer lugar, para escuchar una historia de vida hemos de encontrarnos en una actitud abierta, con la mente despierta y el corazón atento a las complicidades que se vayan desprendiendo del diálogo ${ }^{11}$. En segundo lugar, hemos de huir de plantear preguntas cerradas, presentando un tipo de entrevista bastante abierto y dejando que el informante hable y hable hasta la saciedad, pues sólo de esta forma obtendremos las claves que nos permitan interpretar su visión de la realidad y tamizar los hechos que la memoria ha ido transformando. Evidentemente, como veremos más adelante, estableccremos unas preguntas o bloques temáticos hacia los que conduciremos a nuestro informante, pero nos parece fundamental darle libertad para que se exprese sin cortapisas $^{12}$. Esta libertad viene además reforzada por el hecho de que, cumpliendo uno de los requisitos tradicionales de la Antropología Cultural, nuestros informantes son siempre anónimos, un anonimato que supone, por un lado, respeto a su persona y a la confidencialidad de su testimonio y que, por otro lado, nos permite una mayor libertad a la hora de interpretar.

A la luz de esta total libertad de expresión nos daremos cuenta de que tan importante es lo que se dice como lo que se calla, y tan importante lo que se cuenta como la mane-

10 En la forma de plantear nuestra entrevista nos confesamos deudores de la merodología expuesta por $\mathrm{M}^{\mathrm{x}}$. Dolores PÉREZ MURILLO, Oralidad e historias de vida..., 2000, pp. 26-28, si bien hemos tenido que adaplarla a nuestro propio campo de estudio.

11 PËREZ MURII.LO describe esta actitud de escucha de una manera muy grálica: "Mientras se realiza la entrevista hay que olvidarse de "academicismos", estar cercano y ejercer de psicólogo, sociólogo, antropólogo, historiador; pero ante todo ser persona humana y solidaria con la historia narrada" (Oralidad e hislorias de vida... 2000, p. 28).

12 Si bien nosotros optamos por la elaboración de un guión que nos sirva para conducir la entrevisia, aunque sin renunciar por ello a dar via librc a la cspontaneidad de nuestros informantes, también nos parece muy interesante la labor desamollada por Beatriz VITAR obtenicndo testimonins totalmente espontáneos sin la utilización de un cuestionario previo (VITAR, Op. Cil., p.308). 
ra de contarlo. No olvidemos que, en la mayoría de los casos, la narración de nuestro pasado no es sino una forma de intentar justificar nuestro presente y, por tanto, según sean las circunstancias de éste, así transmitiremos nuestra propia historia de vida. Para ilustra mejor esta afirmación, baste señalar que puede darse el caso de personas que, emigrando en unas circunstancias más o menos similares, nos presenten sus experiencias de formas totalmente divergentes si, por un lado, se trata de una persona que finalmente ha logrado establecerse legalmente y está trabajando con una cierta seguridad, o si, por el contrario, nuestro narrador continúa aún sin haber legalizado su situación, parado o en unas condiciones laborales precarias. En esta misma línea, consideramos muy interesante destacar las aportaciones de Isabelle Bertaux relativas a las diferencias formales entre las historias de vida narradas por varones y las contadas por mujeres, unas diferencias que subyacen también en muchas de las historias de vida con las que venimos trabajando ${ }^{13}$, y que se muestran particularmente interesantes en los casos en los que se realizan entrevistas colectivas, en especial a varios miembros de una misma familia.

En lo referente a las preguntas o a los bloques temáticos a partir de los cuales se desarrolla cada entrevista, estos van dirigidos a dar luz sobre los siguientes aspectos del proceso migratorio:

a. Causas de la emigración: Se utilizan preguntas muy abiertas, del tipo ¿A qué te dedicabas antes de emigrari4? ¿Cómo es tu pueblo o ciudad de origen? IIáblame de tu familia y de tus amigos; ¿Cómo y por qué te decidiste a marchar?. Como vemos son preguntas tanto directas como indirectas que permiten al informante explayarse en las respuestas, de manera que filtrando sus referencias podemos hacernos una imagen clara de la situación que éste deja atrás y de los motivos que impulsaron su marcha.

b. Financiación del viaje: Evidentemente, los viajes transatlánticos no pueden ser calificados precisamente de baratos, por lo que la financiación del viaje es un elemento fundamental para profundizar en el análisis del grupo social y de la situación económica del migrante ${ }^{15}$. La venta de bienes, los ahorros individuales o familiares, los préstamos de chulqueros ${ }^{16}$, usureros, amigos o parientes más o menos directos, el recurso a empresas especializadas, la hipoteca de los terrenos

13 BERTAUX-WIAME. Isabelle, "La perspcctiva...", 1993, pp. 273-275. A otro nivel, resulta interesante también el análisis que Gioconda HERRERA hace en el Austro Ecuatoriano, sobre la diferente percepción que el entomo familiar demuestra al analizar un proceso de emigración seguin el emigrante sea hombre o mujer (IIF:RRF.RA, Gioconda. "Mig̣ación y familia: una mirada desde el género", p. 4, htp:"'yachana.org/ecuatorianista/encuentro: ponencias herrera. pdf, consultado el 30 de octubre de 2002)

Si bien algunos autores prefieren no cilar el verbo emigrar o los términos emigrante o migración a la hora de realizar la entrevista, pues es cierto que en otros procesos migratorios y en otras circunstancias históricas fueron vistos por muchos como téminos casi despectivos (vėanse, por ejemplo las aportaciones de PÉREZ MURILLO sobre andaluces en Latinoamérica), desde nuestra propia experiencia en la investigación sobre latinoancricanos en España, nos parece adecuado su uso, pues ciertamente. la mayoria de los cntrevistados hasta ahora no sólo no rehuyen la aceptación de su condición de emigrados. sino que en muchos casos, la esgrimen como una manera de justificar determinadas circunstancias de su presente.

15 Utilizamos el término migrante de forma consciente. pues si bien en España este vocablo no es considerado correcto, su uso en algunos paises de América Latina está cada vez más extendido, utilizándose de forma general para referirse a todos aquellos que se han desplazado a otros lugares, independientemente de la perspectiva del obscriador.

16 Chulquero es, en algunas regiones de Latinoamérica, y de forma concreta en Ecuador, el particular que. sin esgrimir las exigeneias de las cntidades financieras, presta dinero a altísimos intereses, exigiendo generalınente como aval la eseritura de las propiedades (terrenos o vivienda) que pueda poseer $\mathrm{el} \mathrm{solicitantc.}$ 
familiares... son algunas de las formas de financiar el pasaje hacia Europa, y la elección de tal o cual recurso, o de varios de ellos combinados, nos aporta muchisima información sobre las condiciones de vida de nuestro informante. Las preguntas en este caso pueden ser más directas, del estilo ¿Cuánto te ha costado el viaje? ¿Cómo lo pagaste? ¿Tuviste que recurrir a alguna ayuda para poder pagar el pasaje?, si bien en algunos casos habremos de dar pequeños rodeos para no ofender al entrevistado, que a veces, ante cuestiones tan directas tiende a retraerse. En tal caso, se le puede preguntar por los bienes y propiedades que dejó al marchar, o si contaba con algo de dinero para ir haciendo frente a las primeras semanas en España, o si envía periódicamente remesas de dinero a sus familiares. Generalmente, los informantes al dar respuesta a estas últimas cuestiones incluyen abundantes detalles sobre los costos y la financiación del viaje.

c. Infraestructura del viaje: Lo fundamental es conocer si se viajó con la documentación en regla o si se emigró de forma ilegal. Si se hizo del primer modo, conviene conocer cómo se consiguieron los permisos y cómo se contactó con las autoridades encargadas de proporcionarlos (teóricamente, en las embajadas y consulados españoles), y si no, hay que indagar sobre cómo se consiguió la infraestructura minima para acceder a España: si se hizo a través de las empresas que organizan los denominados en algunos países viajes redondos ${ }^{17}$, si se disponía de algún familiar ya emigrado que servía de enlace, si se ingresó como turista, si se hizo el vuelo directo a Barajas, el aeropuerto transcontinental de Madrid, o se utilizaron vuelos con escalas en otros aeropuertos europeos... Con estas preguntas, que pudieran parecer más cerradas que las planteadas en apartados anteriores, las coletillas ¿Cómo? y ¿Por $q u e ?$, pueden servir de puerta para dejar el discurso del relato de nuevo en manos del informante. En el caso de que nuestro interlocutor tuviera familia ya instalada en España, preguntarle por estos parientes y por el papel que jugaron en su decisión y en la manera de marchar, puede resultar fundamental para analizar no sólo la percepción de su propia historia, sino la de aquellos que le precedieron en su aventura, a la vez que nos da pie para abrir las reflexiones sobre la existencia o no de redes familiares o de paisanaje en estos movimientos migratorios.

d. La llegada: Con este bloque pretendemos que el informante hable en detalle sobre sus impresiones y depresiones (utilizando los términos de la Dra. Pérez Murillo) al llegar a España. Las preguntas del tipo ¿Cómo te sentiste al llegar? ¿Qué tal fueron tus primeras reacciones? ¿Cómo viviste tus primeros contactos con los españoles?, suelen suscitar respuestas muy amplias en las que los sentimientos de los informantes juegan muchas veces el papel principal, dando lugar en muchas ocasiones a discursos en los que la nostalgia juega un papel protagonista. A su vez, estas contestaciones pueden ser muy ricas a la hora de analizar la percepción que el migrante tiene del español, y viceversa, abriendo el camino al análisis de posibles prejuicios y comportamientos racistas o xenófobos.

17 Se denominan asi, viajes redondos, a aquellos tramitados a iravés de una agencia, supuestamenle legal, que se encarga de todos los preparativos para el viaje, incluyendo no sólo la tramitación de los pasajes, sino también la conceesión, también a clevados intereses, de un préstamo para bacer frente a los cuantiosos gastos del viaje y para poder presentar la bolsa de viaje exigida en Barajas a aqueilos ciudadanos tatinoamericanos que entran en España como turistas. El nivel de organización es tal, que incluso en algunas de estas agencias sc imparten clases a sus clientes sobre cómo ha de ser su comportamiento en el acropuerto para parecer un auténtico turista. 
e. Estrategias de socialización: Tirando de los flecos de las respuestas del bloque anterior, se puede ir analizando la forma en la que el migrante va buscando su lugar en nuestro país, y podemos ir planteando preguntas del tipo ¿Con quién sueles relacionarte? ¿Tus amigos suelen ser de tu mismo pais? ¿Son también inmigrantes? ¿Son latinos? ¿Cómo encontraste tu primer empleo? ¿A qué te dedicas en tu tiempo libre?. Estas preguntas van encaminadas a analizar con mayor profundidad la existencia de redes familiares y de paisanaje que hubiésemos podido contrastar en respuestas anteriores, así como a valorar el nivel de radicación de los migrantes, y estimar en su justa medida la eficacia a nivel real de las posibles políticas de integración que se pudieran estar llevando a cabo.

f. Sistema de valores y mentalidad: Una pregunta muy esclarecedora es la siguiente: ¿Cómo ha cambiado tu vida y la de los tuyos desde que llegaste a España? Esta pregunta tan amplia permite al informante establecer sus prioridades y componer su relato más personal de todo lo que ha implicado el proceso migratorio, siendo reveladora de aspectos esenciales acerca de cómo se reestructuran los sistemas de valores y la mentalidad tras la experiencia de la marcha, constatándose en muchos casos la sensación de haberse convertido en ciudadanos hibridos, que no pertenecen al mundo al que intentan por todos los medios adaptarse, pero que han dejado también de formar parte esencial de la realidad que dejaron atrás al emigrar ${ }^{18}$.

g. Situación en el momento de la entrevista: Es fundamental para dar sentido al resto de la entrevista, pues como decíamos anteriormente, el pasado siempre se ve a través del cristal del presente, y la situación del informante en el momento de ser entrevistado es una de las claves básicas para interpretar correctamente el relato de su historia de vida. Para ello han de formularse preguntas como $i A$ qué te dedicas en la actualidad? ¿Cómo te encuentras ahora? ¿Piensas regresar a tu pais? $\mathrm{Y}$, sobre todo, una pregunta muy reveladora si sabemos interpretar los silencios y el lenguaje no verbal: ¿Ha merecido la pena?.

Grabada y transcrita la entrevista, el trabajo del historiador continúa, debiendo verificar, en la medida de lo posible, los datos más relevantes surgidos en el transcurso de la entrevista, considerando los más que probables deslices de la memoria y comprobando las referencias objetivas señaladas en la narración (fechas, acontecimientos citados, personajes aludidos...), para terminar elaborando de esta forma una completa historia de vida a raíz del testimonio del informante.

De esta manera, el historiador se convierte en intérprete privilegiado y en narrador último de la historia, redactando un relato ordenado, ubicado geográfica y temporalmente y contextualizado en las coyunturas históricas en las que se desarrolla, de manera tal que el resultado final nos debe presentar una doble narración: la de la persona entrevistada, que debe ser absolutamente respetada, y la aportada por el historiador mediante la comprobación, explicación e interpretación del testimonio.

Tal vez de esta forma, desde el vivo diálogo entre el historiador y el informante, podamos liberar de nuevo a la Historia de los corsés academicistas y de los intereses de los poderosos, para devolver, al fin, la voz a sus auténticos protagonistas.

18 En este sentido me parece particularmente hermosa la cita que hace Beatriz VITAR, retomando a Milan KUNDERA. sobre la sensación que tienen los que permanecen en el extranjcro de estar transitando por "un espacio vacio en lo alto, encima de la lierra" (KUNDERA, Milan, La insoportable levedad del ser, citado por VITAR, B., Op. Cit., p. 303). 